\title{
Перенос заряда и термо-ЭДС в соединении $\mathrm{TIGdS}_{2}$
}

\author{
() С.Н. Мустафраева, ${ }^{1}$ С.М. Асадов ${ }^{2}$ \\ ${ }^{1}$ Институт фризики НАН Азербайджана, \\ Az1143 Баку, Азербайджан \\ ${ }^{2}$ Институт катализа и неорганической химии им. акад. М. Нагиева НАН Азербайджана, \\ Az1143 Баку, Азербайджан \\ e-mail: solmust@gmail.com, mirasadov@gmail.com
}

(Поступило в Редакцию 26 января 2016 г. В окончательной редакции 25 ноября 2016 г.)

В образцах соединения $\mathrm{TlGdS}_{2}$ впервые изучены температурные зависимости проводимости на постоянном токе и коэффициента термо-ЭДС в области температур 77-373 К. Установлены $p$-тип проводимости и наличие прыжкового механизма переноса заряда по запрещенной зоне $\mathrm{TlGdS}_{2}$ при низких температурах $(114-250 \mathrm{~K})$. Определены основные параметры локализованных энергетических состояний в запрещенной зоне $\mathrm{TlGdS}_{2}$.

DOI: 10.21883/JTF.2017.07.44679.1744

\section{Введение}

В полупроводниковых материалах, которые содержат комбинацию $p$ - и $f$ - элементов ( $\operatorname{Ln}$ - лантаноиды), проявляются различные фазовые превращения, магнитные свойства, а также имеют место обменные взаимодействия $\mathrm{Ln}^{3+}$-ионов и металлов, валентные электроны которых с наивысшей энергией занимают $p$-орбиталь. Несмотря на определенные достижения в области исследования тройных (и более сложных) халькогенидов с участием p-элементов III группы (Ga, In, Tl) Периодической системы Д.И. Менделеева и халькогенидов лантаноидов, их физические свойства изучены недостаточно [1-5]. Литературные сведения об электрических свойствах этих халькогенидных фаз, в частности, $\mathrm{TlGdX}_{2}$ (где, $\left.\mathrm{X}=\mathrm{S}, \mathrm{Se}, \mathrm{Te}\right)$ скудны. Из измерений намагниченности и магнитной восприимчивости определен эффективный магнитный момент $\mathrm{TlGdS}_{2}: \mu_{\mathrm{eff}}=7.85 \mu_{B}$ ( $\mu_{B}$ - магнетон Бора) [6]. Электрофизические свойства соединения $\mathrm{TlGdS}_{2}$ исследованы значительно меньше, тогда как изучение особенностей переноса заряда в магнитных полупроводниках имеет самостоятельное и техническое значения.

В настоящей работе поставлены цели исследовать температурный ход проводимости, установить механизм проводимости и изучить термоэлектрические свойства соединения $\mathrm{TlGdS}_{2}$.

\section{Методика эксперимента}

Соединение $\mathrm{TlGdS}_{2}$ было синтезировано из исходных чистых элементов T1-000, Gd (Strem, 99.9\%) и S (ос.ч.19-5) способом „прямого синтеза“. Стехиометрическое количество $\mathrm{Tl}, \mathrm{Gd}$ и $\mathrm{S}$ загружали в графитовый тигель таким образом, чтобы металлические элементы Tl и Gd находились с одной стороны, а с другой - сера. Затем тигель с компонентами помещали в кварцевую ампулу, которую вакуумировали до $10^{-3}$ Ра и запаивали.
Заполненную $\mathrm{Tl}$ и Gd часть ампулы погружали в нагретую до $650 \mathrm{~K}$ электропечь, а часть ампулы с содержанием серы находилась вне печи. По мере взаимодействия Tl и Gd с парами серы в течение 3-4h количество серы уменьшалось в конце ампулы. Затем температуру горячей зоны печи постепенно увеличивали сначала до $973 \mathrm{~K}$, а затем до $1350 \mathrm{~K}$ и полностью погружали ампулу в печь. Ампулу выдерживали при этой температуре в течение $3 \mathrm{~h}$. В таких условиях вся исходная сера вступает в реакцию с образованием соединения $\mathrm{TlGdS}_{2}$. Затем печь с ампулой медленно охлаждали до $450 \mathrm{~K}$, проводили отжиг в течение $50 \mathrm{~h}$; после этого печь охлаждали до комнатной температуры.

По данным рентгенофазового анализа (РФА; дифрактометр ДРОН-3 в $\mathrm{Cu} K_{\alpha}$-излучение) полученные образцы $\mathrm{TlGdS}_{2}$ были однородны и не содержали каких-либо внедрений второй фазы, в частности, гадолиния. Параметры кристаллической решетки $\mathrm{TlGdS}_{2}(a=0.4052 \mathrm{~nm}$,

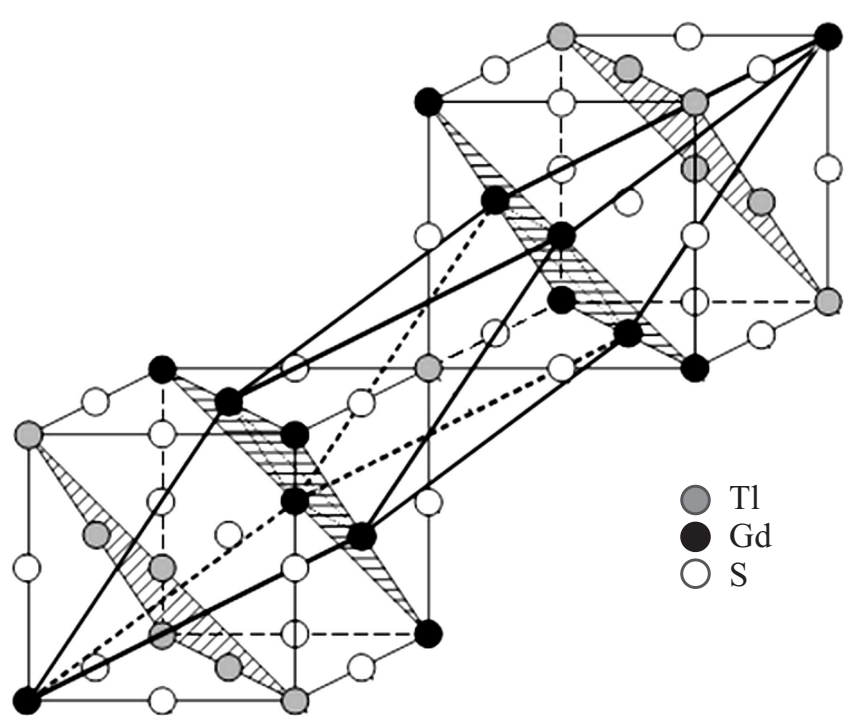

Рис. 1. Структура кристалла $\mathrm{TlGdS}_{2}$. 


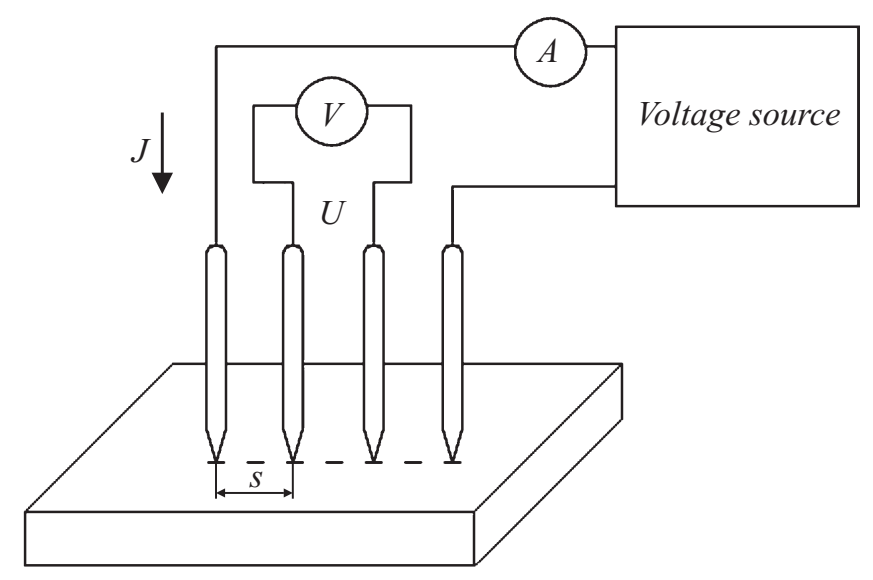

Рис. 2. Электрическая схема измерения удельного сопротивления $\mathrm{TlGdS}_{2}$ четырехзондовым методом.

$c=2.2404 \mathrm{~nm})$ с ромбоэдрической структурой типа $\alpha$ $\mathrm{NaFeO}_{2}$ (пространственная группа $D_{3 d}^{5}-R \overline{3} m$ ) (рис. 1) совпадали с данными [6].

Для измерения электросопротивления полученным образцам $\mathrm{TlGdS}_{2}$ придавали форму параллелепипеда размерами $5.8 \times 3.77 \times 1.68 \mathrm{~mm}$. Измерения удельного сопротивления образцов $\mathrm{TlGdS}_{2}$ осуществлены четырех зондовым методом [7]. Схема измерения представлена на рис. 2. На плоской поверхности образца вдоль прямой линии были размещены четыре металлических зонда на одинаковом расстоянии $(s)$ друг от друга. Через внешние зонды пропускался электрический ток $J$, а на внутренних зондах измерялась разность потенциалов $U$. Измеренные значения $J$ и $U$ позволили определить удельное сопротивление образца по формуле [7]

$$
\rho=2 \pi s \frac{U}{J} .
$$

Термо-ЭДС в образцах измерена дифференциальным методом [8]. Перепад температур $\Delta T$ между двумя точками на образце измерялся с помощью двух термопар, а сигнал термо-ЭДС $\Delta V$ измерялся по одноименным ветвям термопар. Для измерения термо-ЭДС использованы термопары медь-константан, а в качестве электрода сравнения использована медь. Термо-ЭДС определяли по формуле

$$
\alpha=-\frac{\Delta V}{\Delta T}+\alpha_{l},
$$

где $\alpha_{l}$ - абсолютная термо-ЭДС электрода сравнения.

Электрическая проводимость $(\sigma)$ и термо-ЭДС $(\alpha)$ полученных образцов измерены с точностью до $3-5 \%$ в температурном диапазоне $77-373 \mathrm{~K}$.

\section{Результаты и их обсуждение}

Рассмотрим полученные нами результаты изучения процессов переноса заряда в $\mathrm{TlGdS}_{2}$ в постоянном электрическом поле из омического участка вольтамперной характеристики. На рис. 3 показана типичная температурная зависимость проводимости для образцов $\mathrm{TlGdS}_{2}$.

Высокотемпературная ветвь приведенной зависимости носила экспоненциальный характер и имела наклон $E_{t}=0.2 \mathrm{eV}$ в области температур $250-373 \mathrm{~K}$. После экспоненциального спада проводимость в координатах Аррениуса характеризовалась монотонно убывающей энергией активации с уменьшением температуры вплоть до $T=170 \mathrm{~K}$. Этот факт свидетельствует в пользу того, что при температурах из интервала $170-250 \mathrm{~K}$ перенос заряда в образцах $\mathrm{TlGdS}_{2}$ осуществляется с помощью прыжковой проводимости с переменной длиной прыжка по состояниям, лежащим в узкой полосе энергий $(\Delta E)$ вблизи уровня Ферми. Такого типа проводимость обычно наблюдается в аморфных, поликристаллических и сильно легированных и компенсированных полупроводниках и описывается формулой [9]

$$
\begin{gathered}
\sigma \sim \exp \left[-\left(T_{0} / T\right)^{1 / 4}\right], \\
T_{0}=\frac{16}{k N_{F} a^{3}},
\end{gathered}
$$

где $k$ - постоянная Больцмана, $N_{F}$ - плотность локализованных состояний вблизи уровня Ферми, $a-$ радиус локализации.

Экспериментальные результаты по электропроводности для образца $\mathrm{TlGdS}_{2}$ при $T=170-250 \mathrm{~K}$, перестроенные в координатах Мотта $\left(\lg \sigma\right.$ от $\left.T^{-1 / 4}\right)$, приведены на рис. 4. В указанных координатах экспериментальные точки спрямлялись. Спрямление температурной зависимости проводимости в координатах $\lg \sigma$ от $T^{-1 / 4}$ подтверждает наличие моттовской проводимости в образцах $\mathrm{TlGdS}_{2}$.

Наклон полученной зависимости составлял $T_{0}=$ $=5.5 \cdot 10^{6} \mathrm{~K}$. По формуле (4) оценили плотность локализованных вблизи уровня Ферми состояний: $N_{F}=$

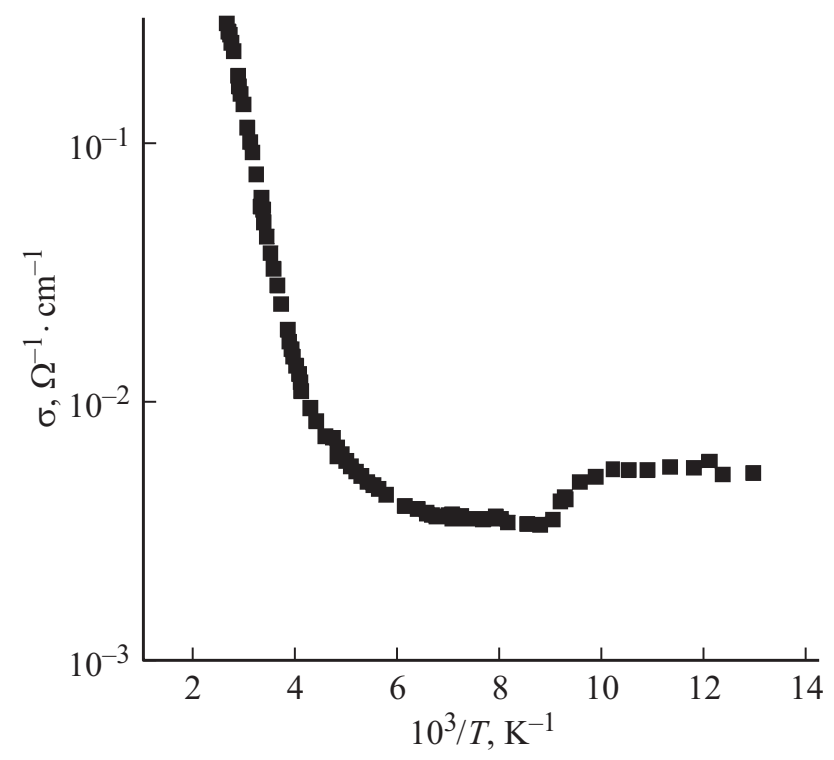

Рис. 3. Температурная зависимость проводимости образца $\mathrm{TlGdS}_{2}$ на постоянном токе в координатах Аррениуса. 


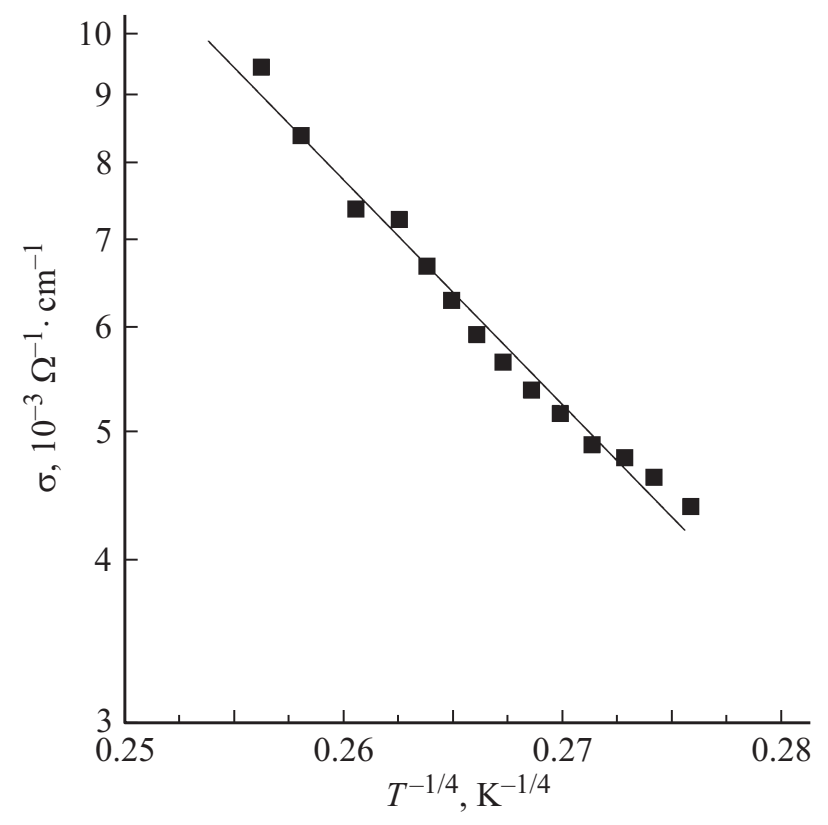

Рис. 4. Низкотемпературная ветвь зависимости проводимости образца $\mathrm{TlGdS}_{2}$, перестроенная в координатах Мотта.

$=1.25 \cdot 10^{18} \mathrm{eV}^{-1} \cdot \mathrm{cm}^{-3}$. При этом для радиуса локализации взято значение $a=3.0 \mathrm{~nm}$ [4] (по аналогии c $\mathrm{TlErTe}_{2}$ ). Полученное для $N_{F}$ достаточное высокое значение свидетельствует о том, что исследуемые образцы $\mathrm{TlGdS}_{2}$ по своей энергетической структуре близки к аморфным полупроводникам. Как известно, для аморфного состояния характерно наличие сильно деформированных и даже разорванных химических связей, которые склонны к проявлению акцепторных свойств. Существованием таких дефектов и объясняется, в частности, высокая плотность состояний вблизи уровня Ферми. Вносила свой вклад в увеличение степени разупорядочения, приводящей, в свою очередь, к значительной концентрации локализованных в запрещенной зоне состояний, и поликристалличность полученных образцов $\mathrm{TlGdS}_{2}$. Наличие дефектных центров высокой концентрации обусловливает заметную проводимость по локализованным состояниям в запрещенной зоне даже и при сравнительно высоких температурах.

По формуле

$$
R=\frac{3}{8} \alpha\left(T_{0} / T\right)^{1 / 4}
$$

определили расстояния прыжков в образце $\mathrm{TlGdS}_{2}$ при различных температурах. Так, при $T=170 \mathrm{~K}$ $R=15.1 \mathrm{~nm}$, а при $T=250 \mathrm{~K} R=13.7 \mathrm{~nm}$. Среднее расстояние прыжков в указанном интервале температур составляло $R_{\mathrm{av}}=14.4 \mathrm{~nm}$, а отношение $R_{\mathrm{av}} / a$ было равно 4.8 , т. е. среднее расстояние прыжков существенно превышало среднее расстояние между центрами локализации носителей заряда.
По формуле [9]

$$
\Delta E=\frac{3}{2 \pi R^{3} N_{F}}
$$

оценили энергетический разброс ловушечных состояний вблизи уровня Ферми: $\Delta E=128 \mathrm{meV}$. Именно в этой энергетической полосе $\Delta E$ в запрещенной зоне $\mathrm{TlGdS}_{2}$ происходит прыжковый перенос заряда. При этом энергия активации прыжков в $\mathrm{TlGdS}_{2}$, определенная по формуле [10]

$$
\Delta W=\frac{(k T)^{3 / 4}}{\left[N_{F} \alpha^{3}\right]^{1 / 4}},
$$

в интервале температур $170-250 \mathrm{~K}$ в среднем составляла $\Delta W_{\mathrm{av}}=114 \mathrm{meV}$, т. е. была несколько меньше, чем $\Delta E$.

Нами оценена также концентрация локализованных состояний, ответственных за перенос заряда в $\mathrm{TlGdS}_{2}$ на постоянном токе: $N_{t}=N_{F} \cdot \Delta E=1.6 \cdot 10^{17} \mathrm{~cm}^{-3}$.

В рассмотренной выше области температур $170-250 \mathrm{~K}$ при прыжках носителей заряда с одного локализованного центра на другой поглощаются фононы. Наличие энергии активации, монотонно уменьшающейся с понижением температуры, связано с разбросом локализованных уровней по энергиям. С понижением температуры растет вероятность прыжков носителей заряда на пространственно более удаленные, но энергетически более близкие центры, что и является причиной убывания энергии активации прыжков по мере уменьшения температуры. Постепенно энергия активации прыжков сходит на нет, т.е. проводимость перестает зависеть от температуры. Согласно [10], в таком случае прыжки носителей заряда происходят с испусканием фононов.

Из наших экспериментальных результатов следует, что безактивационная прыжковая проводимость в $\mathrm{TlGdS}_{2}$ имеет место при температурах $T<170 \mathrm{~K}$ вплоть

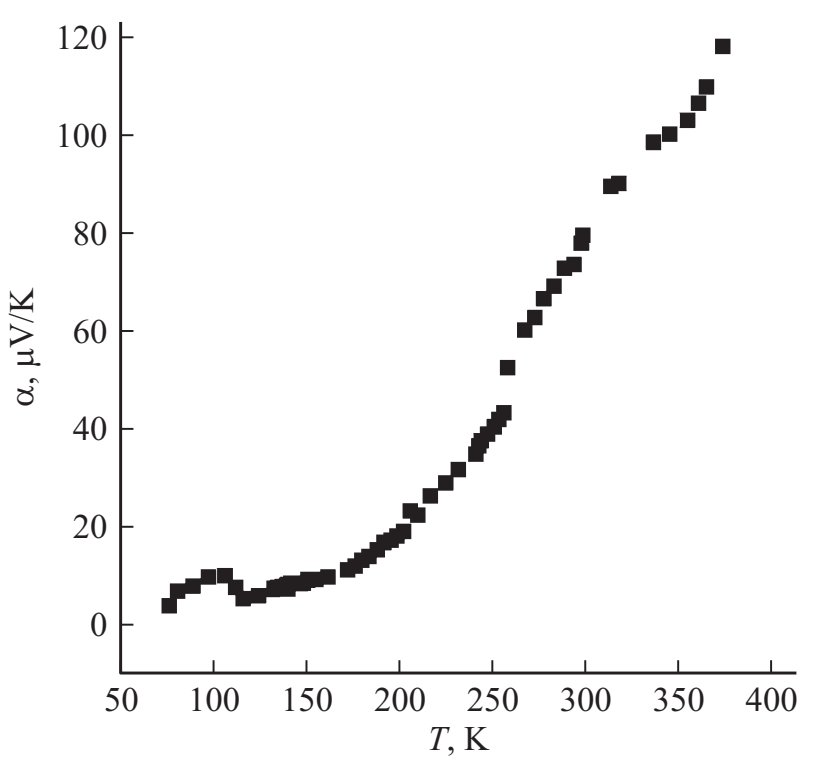

Рис. 5. Температурная зависимость коэффициента термо-ЭДС в $\mathrm{TlGdS}_{2}$. 


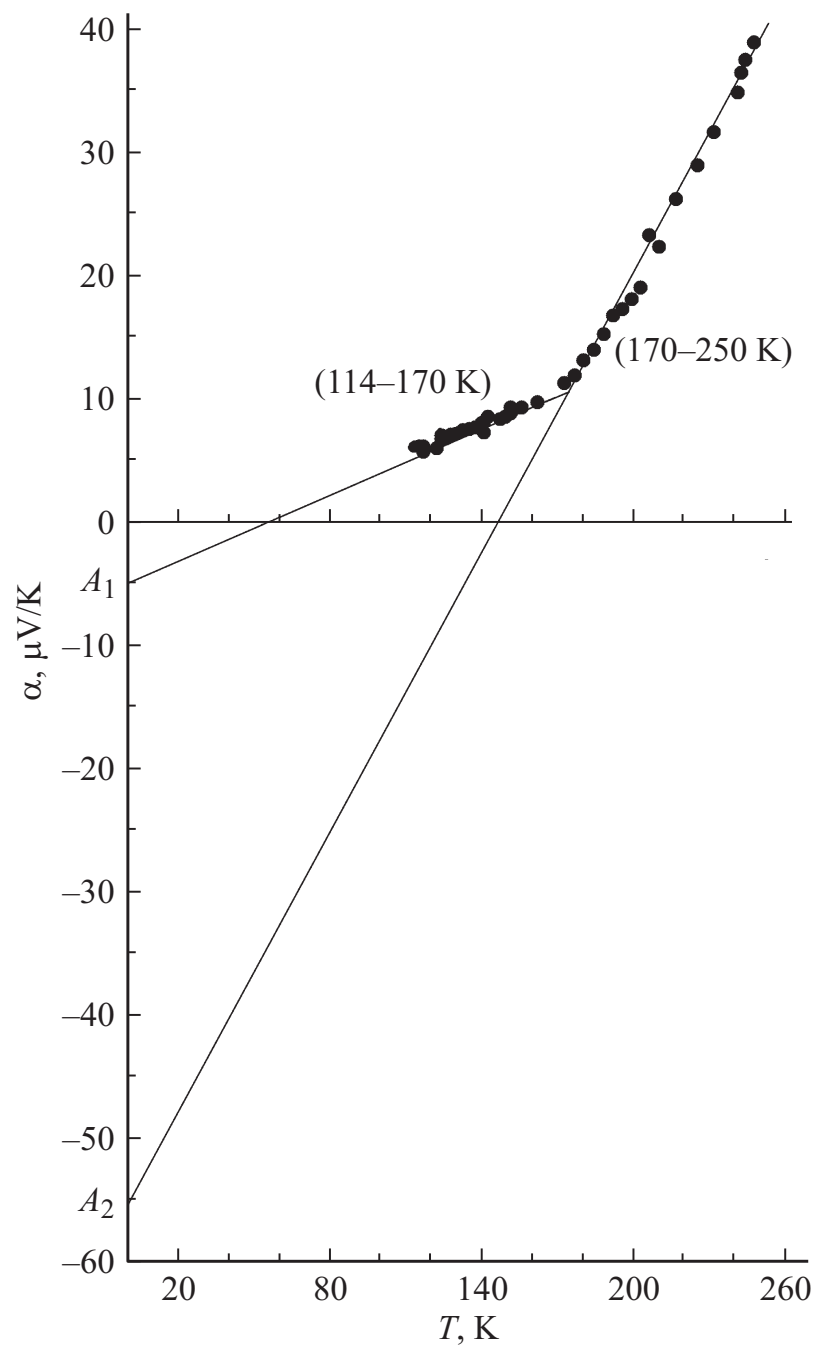

Pис. 6. Температурная зависимость термо-ЭДС в $\mathrm{TlGdS}_{2}$ в области безактивационной и активационной прыжковой проводимости.

до $114 \mathrm{~K}$. При более низких температурах $(T<110 \mathrm{~K})$ на зависимости $\lg \sigma(1 / T)$ наблюдалось увеличение проводимости. Небольшая аномалия при этих же температурах наблюдалась также на температурной зависимости термо-ЭДС в $\mathrm{TlGdS}_{2}$ (рис. 5).

Эту аномалию на рис. 5, по-видимому, можно связать с тем, что в кристаллах со структурой типа $\alpha-\mathrm{NaFeO}_{2}$ могут быть фазовые переходы [11]. В частности, результаты исследования магнитных свойств и теплоемкости $\mathrm{TlGdS}_{2}[12]$ показали, что в них ниже $75 \mathrm{~K}$ расположен фазовый переход ферромагнетик-парамагнетик.

Из рис. 5 следует, что во всей изученной области температур 77-373 K знак термо-ЭДС положителен, что свидетельствует о том, что $\mathrm{TlGdS}_{2}$ имеет $p$-тип проводимости. По мере увеличения температуры величина термо-ЭДС возрастала. Максимальное значение термо-ЭДС в $\mathrm{TlGdS}_{2}$ составляло $\alpha=118.2 \mu \mathrm{V} / \mathrm{K}$ при $T=373 \mathrm{~K}$.
Теперь проанализуруем температурную зависимость термо-ЭДС в $\mathrm{TlGdS}_{2}$ в области прыжковой проводимости. Согласно [9] формула для термо-ЭДС халькогенидных полупроводников в перескоковой области имеет вид

$$
\alpha(T)=A+B T,
$$

где $B$ - температурный коэффициент термо-ЭДС.

На рис. 6 приведена температурная зависимость $\alpha$ в области низких температур $(114-250 \mathrm{~K})$, при которых в $\mathrm{TlGdS}_{2}$ отмечена прыжковая проводимость. Видно, что полученная нами зависимость $\alpha(T)$ линейно зависит от температуры в соответствии с уравнением (8). При этом кривая $\alpha(T)$ характеризовалась двумя наклонами $B_{1}$ и $B_{2}$. В области температур $114-170 \mathrm{~K}$, где наблюдалась безактивационная прыжковая проводимость, тангенс угла наклона зависимости $\alpha(T)$ составлял $B_{1}=0.1 \mu \mathrm{V} / \mathrm{K}^{2}$. Термо-ЭДС отсечки $\left(A_{1}\right)$ при $T=0$ составляла $-5 \mu \mathrm{V} / \mathrm{K}$. То есть в указанной области температур $(114-170 \mathrm{~K})$ термо-ЭДС в $\mathrm{TlGdS}_{2}$ аппроксимируется следующей формулой:

$$
\alpha_{1}(T)=(0.1 T-5) \mu \mathrm{V} / \mathrm{K} .
$$

В температурной области $170-250 \mathrm{~K}$, когда имело место монотонное изменение энергии активации проводимости с изменением температуры, температурный коэффициент термо-ЭДС был в 4 раза выше:

$$
B_{2}=\frac{\partial \alpha}{\partial T}=0.4 \mu \mathrm{V} / \mathrm{K}^{2},
$$

а термо-ЭДС отсечки $A_{2}$ составляла $-56 \mu \mathrm{V} / \mathrm{K}$. То есть, при $T=170-250 \mathrm{~K}$ термо-ЭДС в $\mathrm{TlGdS}_{2}$ подчинялась закономерности

$$
\alpha_{2}(T)=(0.4 T-56) \mu \mathrm{V} / \mathrm{K} .
$$

Поскольку термо-ЭДС в основном определяется плотностью состояний, в перескоковой области ее знак положителен. Таким образом, при низких температурах, когда преобладает прыжковая проводимость, термо-ЭДС в $\mathrm{TlGdS}_{2}$ положительна и пропорциональна температуре.

\section{Заключение}

Полученные нами экспериментальные результаты по изучению процессов переноса зарядов в образцах $\mathrm{TlGdS}_{2}$ в широкой области температур $(T=77-373 \mathrm{~K})$ позволяют утверждать, что в $\mathrm{TlGdS}_{2}$ в области температур $250-373 \mathrm{~K}$ наблюдается примесная проводимость с энергией активации $0.2 \mathrm{eV}$, а при низких температурах $(170-250 \mathrm{~K})$ имеет место прыжковая проводимость с монотонно уменьшающейся с температурой энергией активации, переходящая в безактивационную прыжковую проводимость при $T<170 \mathrm{~K}$. Для $\mathrm{TlGdS}_{2}$ оценены плотность локализованных состояний вблизи уровня Ферми $\left(N_{F}=1.25 \cdot 10^{18} \mathrm{eV}^{-1} \cdot \mathrm{cm}^{-3}\right)$ и их энергетический разброс $(\Delta E=128 \mathrm{meV})$, энергия активации $(\Delta W=114 \mathrm{meV})$ и среднее расстояние прыжков 
$(R=14.4 \mathrm{~nm})$. Установлено, что в условиях прыжковой проводимости знак термо-ЭДС в $\mathrm{TlGdS}_{2}$ был положителен, а температурная зависимость $\alpha(T)$ была линейна $\alpha \sim T$.

Авторы благодарят Джаббарова А.И. за электрические измерения.

\section{Список литературы}

[1] Мустафаева С.Н., Асадов М.М., Керимова Э.М. // ФТТ. 2013. T. 55. № 12. C. 2346-2350.

[2] Mustafaeva S.N., Kerimova E.M., Gasanov A.I. // Acta Physica Polonica A. 2015. Vol. 128. N 4. P. 697-699.

[3] Мустафаева С.Н., Асадов М.М., Керимова Э.М., Гасанов Н.3. // Неорган. материалы. 2013. Т. 49. № 12. С. 12711276.

[4] Mustafaeva S.N., Pashaev A.M., Kerimova E.M. // Azerb. J. Phys. 2013. Vol. 19. N 2. P. 43-45.

[5] Мустафаева С.Н., Асадов М.М., Гусейнов Д.Т. // ЖТФ. 2011. Т. 81. Вып. 1. С. 144-147.

[6] Duczmal M., Pawlak L., Pokrzywnicki S. // Acta Physica Polonica A. 2000. Vol. 97. N 5. P. 839-842.

[7] Павлов Л.П. Методы измерения параметров полупроводниковых материалов. М.: Высшая школа, 1987. 239 с.

[8] Бурков А.Т., Федотов А.Н., Касьянов А.А., Пантелеев Р.И., Накама Т. // Науч.-техн. вестн. информ. техн., механики и оптики. 2015. Т. 15. № 2. С. 173-175.

[9] Мотm Н., Дэвис Э. Электронные процессы в некристаллических веществах. М.: Мир, 1974. 472 с.

[10] Шкловский Б.И., Эфрос А.Л. Электронные свойства легированных полупроводников. М.: Наука, 1979. 351 с.

[11] Безносиков Б.В., Александров К.С. // Журн. структур. химии. 2009. Т. 50. № 1. С. 108-113.

[12] Садыхов Р.З., Наджафзаде М.Д., Керимова Э.М., Алджанов М.А. // ФТТ. 2015. Т. 57. Вып. 2. С. 305-306. 